\title{
Simulation Study of Elliptical Thin Walled Structure Crash Box with Holed Initiator through Axial and Oblique Impact
}

\author{
Jeffery Jep Brown ${ }^{1}$, Al Emran bin Ismail ${ }^{2}$, Dave Kidau anak Willie Chiak Mong ${ }^{3}$ \\ ${ }^{1}$ Research Scholar: Faculty of Mechanical and Manufacturing Engineering, University Tun Hussein Onn \\ Malaysia, Malaysia, jejep007@gmail.com \\ ${ }^{2}$ Professor Faculty of Mechanical and Manufacturing Engineering, University Tun Hussein Onn Malaysia, \\ Malaysia, emran@uthm.edu.my.com \\ ${ }^{3}$ Final Year Student: Faculty of Mechanical and Manufacturing Engineering, University Tun Hussein Onn \\ Malaysia, Malaysia, cd160043@ siswa.uthm.edu.my
}

\begin{abstract}
Crash box is a thin walled structure which is used as a medium for energy absorption to increase crashworthiness of vehicles during accidents by reducing impact or energy received by passengers in the passenger compartment of a vehicle. This study is dedicated to analyse the energy absorption performance of A36 steel elliptical shaped crash box with holed initiators using ANSYS simulation software by analysing effects of holes on elliptical shaped crash box by subjecting it to axial and oblique impact. Each designed elliptical crash box with holed initiator is analysed using performance indicators such as energy absorption value, crush force efficiency and specific energy absorption as to understand effects of holes on elliptical shaped crash box while comparing energy absorption performance of crash box during axial and oblique impact.
\end{abstract}

Key words: Elliptical crash box, Crashworthiness, holed initiator, ANSYS, axial impact, oblique impact

\section{INTRODUCTION}

To increase crashworthiness or energy absorption of vehicles, the introduction of thin-walled structures such as crash boxes have been introduced in automobile industry as a medium to reduce impact energy. The advantage of thin walled structures is that they are lightweight and could reduce fabrication cost while having excellent energy absorption characteristics [1]. Thin walled structures reduce impact energy due to the fact that it deforms plastically during impact thus dissipates impact energy and reduces the amount of energy which could be felt by the passengers [2]. Thin walled structures such as crash box is touted as a viable alternative due to its high energy absorption characteristics, being lightweight, and low cost. Although, the energy absorption characteristics is highly dependent on many factors such as its geometrical shape, material and other characteristics [3], [4].
There is a plethora of research that has been carried out in improving the energy absorption of a thin walled structures such as crash box due to direct axial impact [4]. Such as experiment done upon thin walled kenaf fibre structure subjected to axial loading in order to investigate the crushing responses of that structure.[5], [6] However, during vehicle collision or car accidents energy absorbers such as crash box are subjected to both axial and oblique impact. Not to mention that each thin walled structure systems performs differently in terms of energy absorption performance [1].

Ali \& Hamedani which experimentally analyse frusta, hexagonal tubes, square tubes, rectangular, triangular and pyramidal systems and found that circular tubes have the highest energy absorption capabilities and mean crushing force while also produced a progressive folding mode which would increase energy absorption performances. Although, they neglected testing elliptical shaped thin walled structures in which might have a better energy absorption performance due to its surface area or through different deformation modes.

Gao, Liangmo, Yuanlong \& Wang [2] in 2016 where they investigated foam-filled elliptical tubes under oblique loading using aluminium A6060 T4 and discovered that energy absorption performance of foam filled elliptical thin walled structure is the highest of all structures tested. In addition, the elliptical thin walled structure is also shown to have the highest performance in specific energy absorption than circular, square and rectangular [7]. In addition, Marzbanrad, Mehdikhanlo \& Saeedi [8] have also discovered that aluminium elliptical thin walled structure performs far better than aluminium circular and square but steel type elliptical thin walled structure fared less compared to circular and square structure.

Thin walled structures usually have an ideal energy absorption performance after optimization design although its crushing behaviour is sensitive to imperfections. Such that researchers have investigated ways in decrease peak initial crush force and desired deformation modes through 
imperfections. One such imperfections is the introduction of holes in the structure. a study done by Hammid, Guo, Chew, Bai, Song, \& Wang [9] in 2018 supports the introduction of holes in thin walled structure as a way of increasing performance of thin walled structures as they conclude that holed thin wall structures have an increased in energy absorption performance and a decrease in peak crushing force both in axial and oblique loading. Besides that, Moradpour, Elyasi, \& Montazeri [10] in 2016 found that too few holes in each row in the thin walled structure would create a non-uniform deformation during folding process while too many holes decreases energy absorption performance of the structure which is not ideal and would negate to objective of creating thin walled structure.

Recent advancements in technology has shifted researchers from experimental to computer aided engineering (CAE) simulations (finite element analysis-FEA) based studies [11][12].CAE such as ANSYS is a technique widely used globally in design, analysis and optimization. The CAE simulations reduce the need to manufacture expensive prototypes for physical testing and aid in comparison and improvement of different concepts[1], [13]. Hence, the objective of this study is to design an elliptical thin walled structure crash box with holed initiator as to study energy absorption of the designed crashbox, the effects of introducing holes towards crashworthiness of the crashbox and to compare energy absorption under axial and oblique loads using computer aided engineering (CAE) finite element analysis software such as ANSYS explicit dynamic.

\section{METHODOLOGY}

The elliptical thin walled structure crashbox was modeled using A36. This is because aluminum alloys are widely used in numerous industries such as automotive, microturbine shell and constructions [14], [15]. The length and thickness of the structure was chosen following study done by Tarlochan et al to be $350 \mathrm{~mm}$ and $2 \mathrm{~mm}$ respectively while major and minor axis is set at $62 \mathrm{~mm}$ and $31 \mathrm{~mm}$ respectively [3]. While hole radius was set at $3 \mathrm{~mm}$.

\subsection{Simulation}

The simulation is conducted with impact weightage set at $275 \mathrm{~kg}$ and initial impact velocity $15 \mathrm{~m} / \mathrm{s}$. It was chosen due to the recommended guidelines from New Car Assessment Program (NCAP). The angle of 30 degrees and 5 degrees is chosen due to it being said as the highest load enhancement without a major reduction in mean force and the minimum difference between axial impact [3],[11]. In addition due to it being a nonlinear dynamic to solve a dynamic equilibrium equation problem, the simulation is done using ANSYS explicit dynamics since in explicit dynamic the total time is divided into a smaller time steps or increments in which data of $n+1$ is obtained from previous time step (n) and has no dependence on current time step [17]. Duration of simulation was set at 0.008 seconds with time step safety factor at 0.9 and automatic mass scaling off. Furthermore, erosion controls were used on geometric strain limit and was set at 1.5 in order to avoid problems due to time step errors being too small. Result number of points on output controls were set at 100 .

\subsection{Finite Element Modeling}

The entire structure is comprised of the thin walled structure or crash box and its fixed support base. The thin walled structure was modelled using element sizes of $2 \mathrm{~mm}$ with a surface mesh method of uniform and a mapped mesh method of prism as to avoid time step too small errors which could abruptly end simulation before the required duration. The contact between all bodies was modelled as finite sliding penalty based with the crash box and fixed support bonded together while coefficient of friction is set at 0.2 [17], [18], [19]. The top part and fixed support region were modelled as rigid structure as to prevent deformation. In addition, the top part having one allowable displacement which is until $200 \mathrm{~mm}$ and other displacement either transitional or rotational is fixed. Figure 1 and Figure 2 shows the modelled elliptical thin walled structure crashbox while Table 1 shows the specifications of the designed elliptical thin walled structure crashbox with holed initiator which will be tested with the original non-holed model.

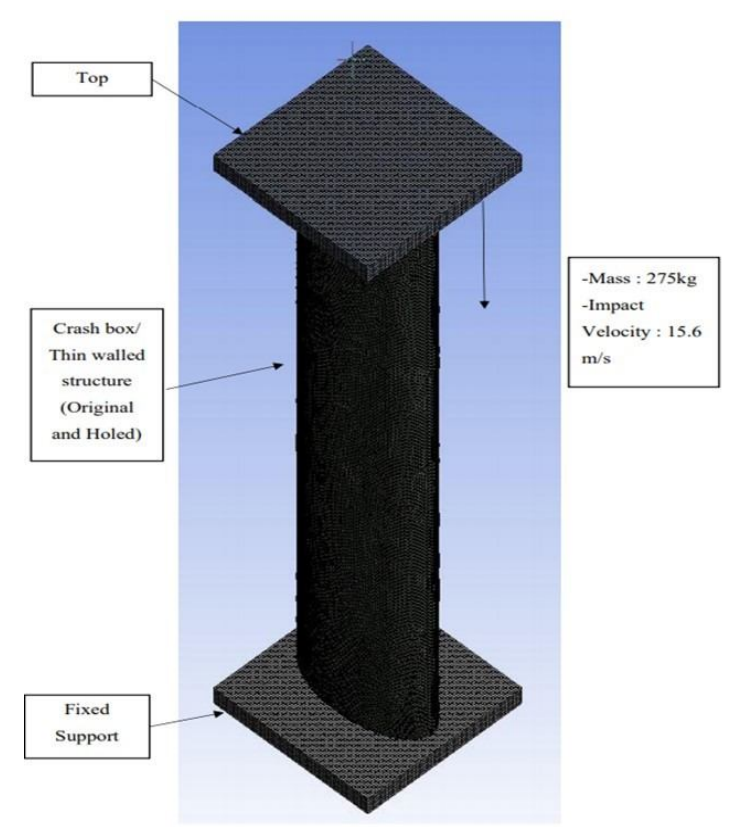

Figure 1: Axial Crash Test 


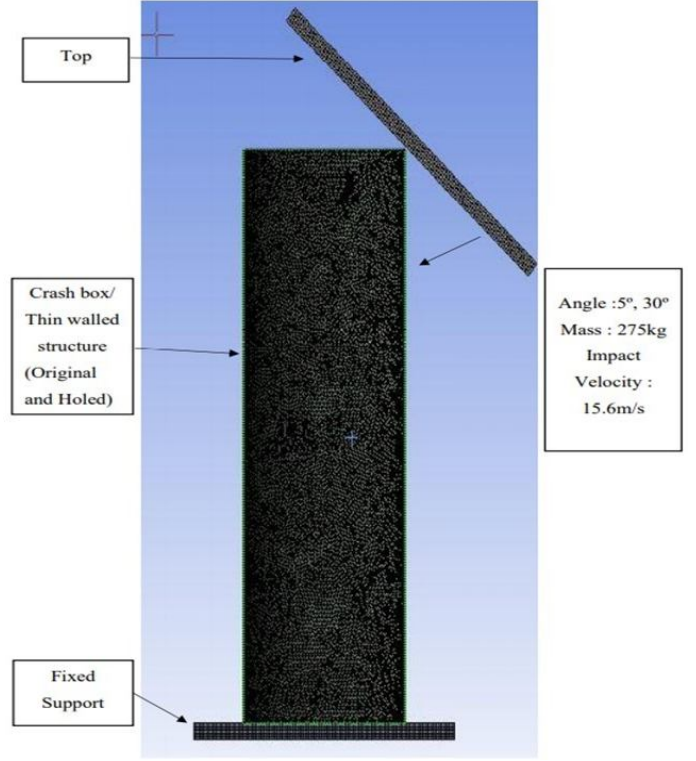

Figure 2: Oblique Crash Test
(CFE) and specific energy absorption (SEA). Energy absorption or energy absorbed, Ea, of the structure is equivalent to the area under the load-displacement curve or graph. Which can be calculated using (1),

$$
E a-\int_{0}^{d \max } F d s
$$

Crush force efficiency (CFE) is the ratio of average force to peak force. A ratio of which when close to 1 is desired for an ideal energy absorber or crashbox can be determined using the equation (2),

$$
\text { GFF }-\frac{\text { Faverage }}{\text { Fmax }}
$$

Specific energy absorption, SEA is the energy absorbed by the structure per unit mass of the structure, where it could be calculated using the equation (3),

$$
\text { SEA }=\begin{gathered}
\text { Enorgy absorbed by structure } \\
\text { Mass of structure }
\end{gathered}
$$

\begin{tabular}{|c|c|c|c|c|c|}
\hline Model & Original & $\begin{array}{c}1^{\text {st }} \\
(3 \times 3)\end{array}$ & $\begin{array}{c}2^{\text {nd }} \\
(5 \times 5)\end{array}$ & $\begin{array}{c}3^{\text {rd }} \\
(10 x \\
10) \\
\end{array}$ & $\begin{array}{c}4^{\text {th }} \\
(3 \times 5)\end{array}$ \\
\hline $\begin{array}{c}\text { Holes in } \\
X \text {-axis }\end{array}$ & 0 & 3 & 5 & 10 & 3 \\
\hline $\begin{array}{c}\text { Holes in } \\
Y \text {-axis }\end{array}$ & 0 & 3 & 5 & 10 & 5 \\
\hline $\begin{array}{l}\text { No. of } \\
\text { Holes } \\
\text { (Front } \\
\text { Face) }\end{array}$ & 0 & 9 & 25 & 100 & 15 \\
\hline $\begin{array}{l}\text { Total } \\
\text { No. of } \\
\text { Holes }\end{array}$ & 0 & 18 & 50 & 200 & 30 \\
\hline $\begin{array}{c}\text { Spacing } \\
\text { between } \\
\text { holes } \\
\text { (X-axis) }\end{array}$ & - & $\begin{array}{c}50 \\
\mathrm{~mm}\end{array}$ & $\begin{array}{c}24 \\
\mathrm{~mm}\end{array}$ & $\begin{array}{l}10.5 \\
\mathrm{~mm}\end{array}$ & $\begin{array}{c}45 \\
\mathrm{~mm}\end{array}$ \\
\hline $\begin{array}{c}\text { Spacing } \\
\text { between } \\
\text { Holes } \\
\text { (Y-axis) }\end{array}$ & - & $\begin{array}{l}165 \\
\mathrm{~mm}\end{array}$ & $\begin{array}{c}75 \\
\mathrm{~mm}\end{array}$ & $\begin{array}{c}35 \\
\mathrm{~mm}\end{array}$ & $\begin{array}{c}80 \\
\mathrm{~mm}\end{array}$ \\
\hline
\end{tabular}

Table 1: Characterizations of model

\section{Validation of Data}

$(5 \times 3)$

A validation of data was done with recreation of the design ayd settings used during the analysis process done by them so that it could be recreated on the simulation of all holed elliptical shaped crash box or thin walled structure. Besides that, this is also as to get a validation on the effects of the holes on the structure as to get a definitive analysis on its performance when holes are introduced to the structure in tepms of energy absorption, average force, crush force efficiency and graph of load-displacement curve.

\subsection{Performance Criterion}

Performance of crash box will be evaluated by crash response of each crash box design, which are obtained through peak force (Fmax), energy absorption (Ea), crush force efficiency

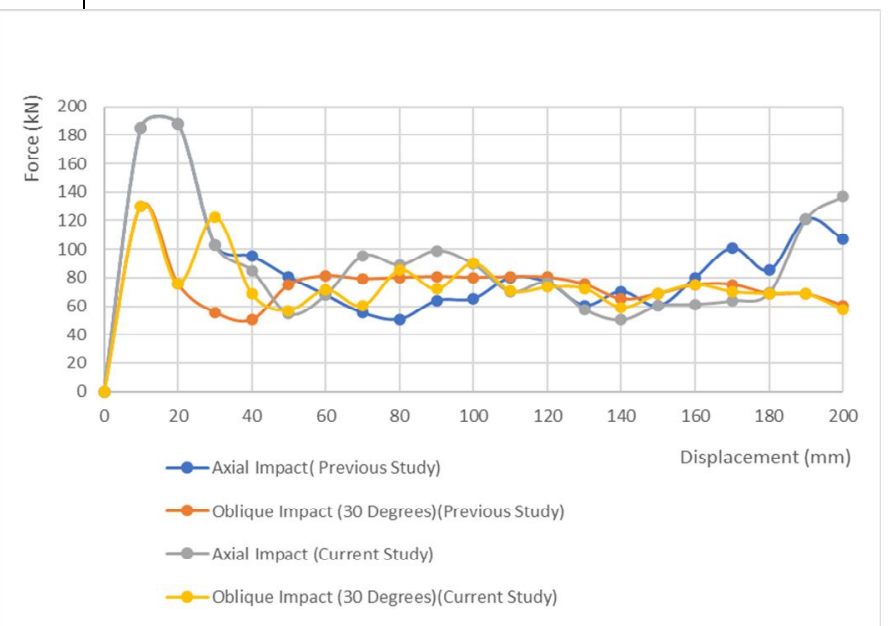

Figure 3: Comparison between previous study graph vs current

study graph with previous study graph of $300 \mathrm{~mm}$ parameter 
Jeffery Jep Brown et al., International Journal of Emerging Trends in Engineering Research, 8(8), August 2020, 4084 - 4090

Table 2: Comparison table between previous study graph vs current study with previous study of $300 \mathrm{~mm}$ parameter

\begin{tabular}{|c|c|c|c|c|}
\hline \multirow{2}{*}{ Indicators } & \multicolumn{2}{|c|}{ Axial/Direct Impact } & \multicolumn{2}{|c|}{$\begin{array}{l}\text { Oblique Impact, } \\
\text { (30 Degrees) }\end{array}$} \\
\hline & $\begin{array}{l}\text { Previous } \\
\text { study }\end{array}$ & $\begin{array}{l}\text { Current } \\
\text { study }\end{array}$ & $\begin{array}{l}\text { Previous } \\
\text { study }\end{array}$ & $\begin{array}{c}\text { Current } \\
\text { study }\end{array}$ \\
\hline $\begin{array}{c}\text { Energy } \\
\text { Absorbed } \\
(\mathbf{k J})\end{array}$ & 17.29 & 17.50 & 14.54 & 14.90 \\
\hline $\mathbf{F}_{\max }(\mathbf{k N})$ & 187.16 & 188.00 & 130.18 & 130.00 \\
\hline $\begin{array}{l}\mathbf{F}_{\text {average }} \\
(\mathbf{k N})\end{array}$ & 85.87 & 86.78 & 72.43 & 72.31 \\
\hline $\begin{array}{l}\text { Crushing } \\
\text { Force }\end{array}$ & 0.46 & 0.46 & 0.56 & 0.55 \\
\hline $\begin{array}{c}\text { Efficiency, } \\
\text { CFE } \\
\text { Specific }\end{array}$ & 10.60 & 10.94 & 8.92 & 9.31 \\
\hline $\begin{array}{c}\text { Energy } \\
\text { Absorption, } \\
\text { SEA }\end{array}$ & & & & \\
\hline
\end{tabular}

From the Figure 3 and Table 2, and error calculations done, it can be seen that there is less than $5 \%$ of error or deviation from the data obtained from ansys study and previous study. While the graph of axial and oblique impact is nearly similar although axial graphs have slight difference in several displacement points but should not be a big factor since the error calculations for energy absorption, peak force and crushing force efficiency is less than $5 \%$. Thus, it can be concluded that data recreation and validation is a success thus the next step of studying the effects of holed initiator on crash box or elliptical structure could then be carried.

Table 3: Axial Crash Test result

\begin{tabular}{|c|c|c|c|c|c|c|}
\hline Model & Original & $\begin{array}{l}1^{\text {st }} \\
(3 \times 3)\end{array}$ & $\begin{array}{l}2^{\text {nd }} \\
(5 \times 5)\end{array}$ & $\begin{array}{l}3^{\text {rd }} \\
(10 x \\
10) \\
\end{array}$ & $\begin{array}{l}4^{\text {th }} \\
(3 \times 5)\end{array}$ & $\begin{array}{l}5^{\text {th }} \\
(5 \times 3)\end{array}$ \\
\hline EA $(\mathbf{k J})$ & 17.5 & 77.2 & 70.2 & 65.6 & 80.2 & 51.9 \\
\hline $\begin{array}{c}\text { Fmax } \\
(\mathbf{k N})\end{array}$ & 188 & 1110 & 1460 & 1540 & 1540 & 1110 \\
\hline $\begin{array}{l}\text { Favg } \\
(\mathbf{k N})\end{array}$ & 86.78 & $\begin{array}{c}370.0 \\
4\end{array}$ & $\begin{array}{c}339.1 \\
4\end{array}$ & $\begin{array}{c}317.6 \\
3\end{array}$ & $\begin{array}{c}391.4 \\
7\end{array}$ & $\begin{array}{c}250.3 \\
3\end{array}$ \\
\hline CFE & 0.46 & 0.33 & 0.23 & 0.21 & 0.25 & 0.23 \\
\hline $\begin{array}{c}\text { SEA } \\
(\mathbf{k J} / \mathbf{k g})\end{array}$ & 10.94 & 48.25 & 44.51 & 43.73 & 50.36 & 32.7 \\
\hline
\end{tabular}

Table 4: Oblique Crash Test at $5^{\circ}$

\begin{tabular}{cccccc}
\hline Model & $\mathbf{1}^{\text {st }}$ & $\mathbf{2}^{\text {nd }}$ & $\mathbf{3}^{\text {rd }}$ & $\mathbf{4}^{\text {th }}$ & $\mathbf{5}^{\text {th }}$ \\
& $(\mathbf{3 x 3})$ & $(\mathbf{5 x 5})$ & $\mathbf{( 1 0 x} \mathbf{1 0})$ & $\mathbf{( 3 \times 5 )}$ & $\mathbf{( 5 x 3 )}$ \\
& & & & & \\
\hline EA (kJ) & 60.6 & 44.40 & 41.70 & 33.50 & 46.7 \\
Fmax & 1100 & 938 & 884 & 636 & 644 \\
\hline
\end{tabular}

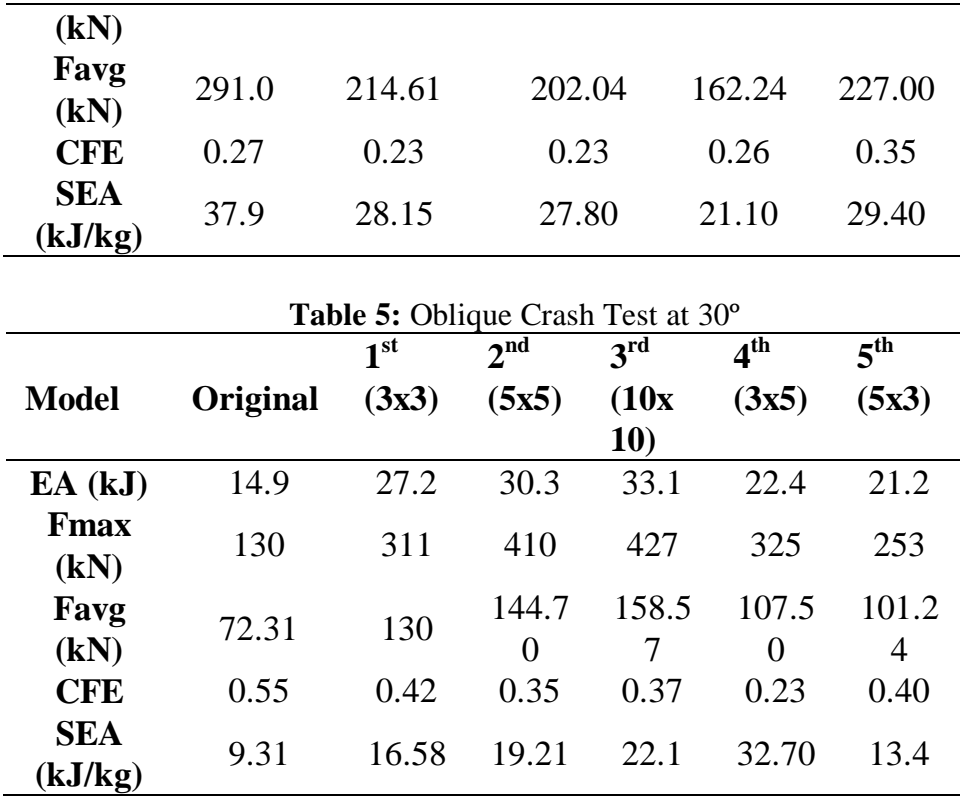

\section{RESULTS AND DISCUSSION}

The results and discussion part will be divided in to two parts of which the first part is the results obtained through simulation using ANSYS explicit dynamics while the second part will be the discussion of the results obtained. From Table 3, Table 4 and Table 5, it is evident that, introducing holes into elliptical crash box does increase energy absorption and specific energy absorption value of the crash box significantly through axial and oblique impact while also increasing its peak force before deformation. Although, the negative effect of it is the crushing force efficiency of the crash box does suffer. A low CFE value of all of the models simply is not viable for a good designed crash box.

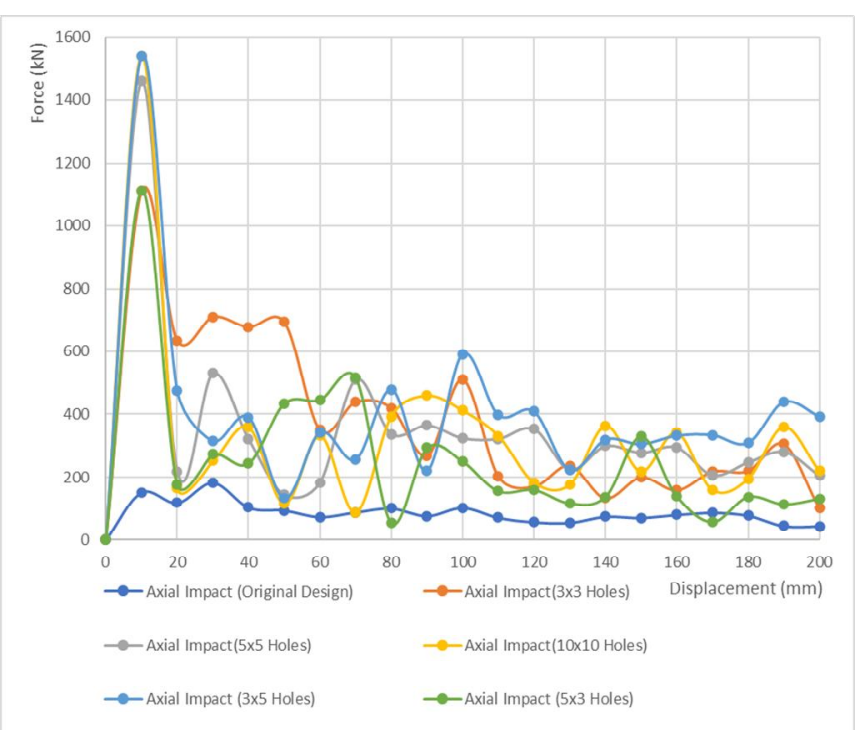

Figure 4: Graph of force vs displacement for axial impact of each model 


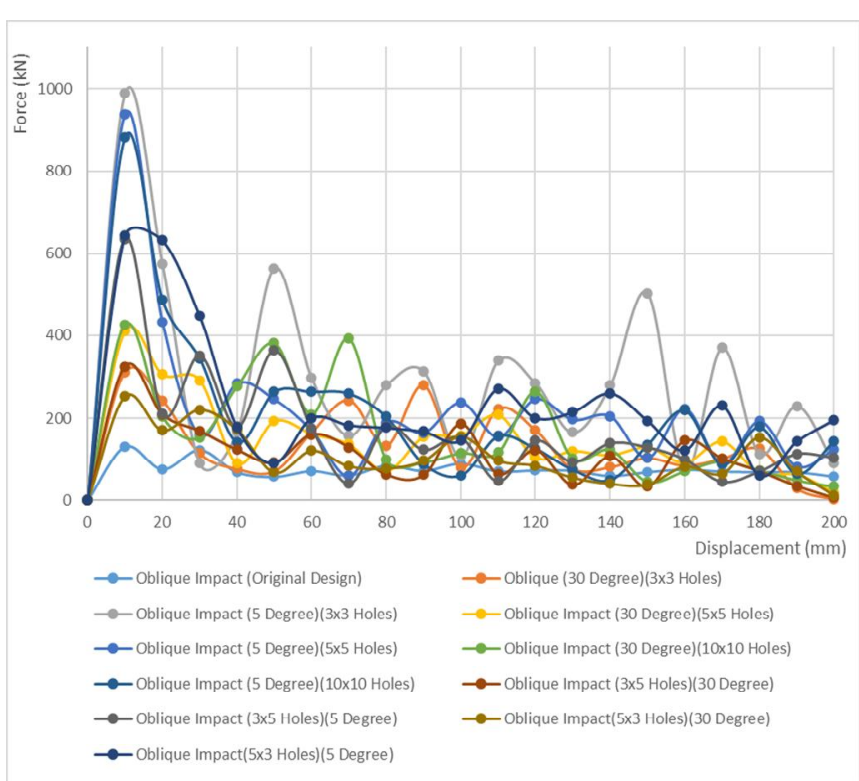

Figure 5: Graph of force vs displacement for oblique impact of each model

Thus, introducing holes on elliptical crash box according to the results is simply not a viable option if CFE value is at the most important. If CFE value is not an important aspect, then introducing holes on the crash box is a great option as to increase the energy absorption of the crash box. The matter of which decrease the CFE value of the elliptical crash box is the peak force which the crash box generates and the rapid decrease in forces after the peak force is achieved as could be seen in graph of Figure 4 and Figure 5. A reason why probably the peak force increase is due to the force being distributed along the crash box. This is seen when vertical holes are introduced in the crash box in which by example of $3 \times 5$ holes where more holes are introduced vertically did increase the peak force generated. Thus, holes in the vertical direction do affect heavily on the peak force of the crash box. Another reason is due to the moment of inertia of the crash box. When evaluating each designed model, it is observed that the moment of inertia is increased in proportional to the increase in the number of holes introduced to the crash box. All of the designed elliptical crash box with holed initiator was found to have an increased moment of inertia value than the original elliptical crash box of the previous study.

Table 6: Difference in Energy Absorption from axial and oblique crash test

\begin{tabular}{cccccc}
\hline Model & Axial & $\begin{array}{c}\text { Oblique } \\
\left.\mathbf{( 3 0}^{\mathbf{}}\right)\end{array}$ & $\begin{array}{c}\text { Differenc } \\
\mathbf{e} \\
(\mathbf{\%})\end{array}$ & $\begin{array}{c}\text { Oblique } \\
\left(\mathbf{5}^{\mathbf{}}\right)\end{array}$ & $\begin{array}{c}\text { Differenc } \\
\mathbf{e} \\
(\mathbf{\%})\end{array}$ \\
\hline $\mathbf{3 x 3}$ & 77.20 & 27.20 & 64.77 & 60.60 & 21.50 \\
$\mathbf{5 x 5}$ & 70.20 & 30.30 & 56.84 & 44.40 & 36.75 \\
$\mathbf{1 0 x 1 0}$ & 65.60 & 33.10 & 49.54 & 41.70 & 36.43 \\
$\mathbf{3 x 5}$ & 80.20 & 22.40 & 72.07 & 33.50 & 58.23 \\
$\mathbf{5 x 3}$ & 51.90 & 21.20 & 59.15 & 46.70 & 10.01 \\
\hline
\end{tabular}

-

Auth Authors acknowledge the financial support to Research Fund E15501, Research Management Centre, Universiti Tun Hussein Onn Malaysia.

From Table 6, it can be seen that the average differences between axial and $30^{\circ}$ oblique impact for the models are between $50-75 \%$ while the average difference between axial and $5^{\circ}$ oblique impact is $10-58 \%$. It can be seen also that when an equal number of holes are added in axial and vertical direction such as in the case for models where the holes are of $3 \times 3,5 \times 5$ and $10 \times 10$ holes. The axial energy absorption of the holes decreases in proportional to the number of holes added to the crashbox, while oblique impact increases in proportional to the increase number of holes added to the crashbox in which the percentage difference would than decrease. Furthermore, it is also evident, that holes added vertically have a larger effect on the energy absorption performance of the crashbox than holes added in horizontal as could be seen when comparing axial impact of $3 \times 5$ holes with $5 \times 3$ holes. When oblique impact $5^{\circ}$ angle was compared with axial impact, it can be seen that with a lower angle of impact near to axial or direct impact the energy absorption performance decreases when the number of holes decreases similar to axial impact energy absorption performance. This showed that with different impact angle, energy absorption performance of the elliptical thin walled structure crashbox with holed initiator is different as oblique impact 30 degree shows that when increasing number of holes are created the energy absorption performance should increase by a small margin.

\section{CONCLUSION}

In a nut shell, when holes are introduced on elliptical crash box, energy absorption of the crash box is significantly increased but CFE values are also significantly decreased. Secondly, when peak force has been achieved for elliptical crash box with holed initiator, there is a rapid decrease in force in which decreases CFE value of the structure. Next, when peak force has been achieved, rapid deceleration than stabilization of forces could be observed. If peak force could be decreased, thus CFE value of elliptical holed crash box could increase significantly. Introducing only holes to the design of the crash box is undesirable for crashworthiness since CFE value of the elliptical crash box is low, although decreasing peak force value while maintaining forces at a slow decrease rate would make the elliptical crash box with holed initiator a viable design for crashworthiness application.

Holes in the vertical direction effects energy absorption performance of elliptical crash box more than horizontal holes. Furthermore, increasing number of holes decreases axial impact energy absorption of elliptical crash box with holed initiator while increasing energy absorption performance of elliptical crash box when crash box undergoes oblique impact. Last but not least, angle of impact has an effect on crash box energy absorption performance.

\section{ACKNOWLEDGEMENT}

re 
Jeffery Jep Brown et al., International Journal of Emerging Trends in Engineering Research, 8(8), August 2020,4084 - 4090

\section{REFERENCES}

[1] S. E. Alkhatib, M. S. Matar, F. Tarlochan, O. Laban, A. S. Mohamed, and N. Alqwasmi, "Deformation modes and crashworthiness energy absorption of sinusoidally corrugated tubes manufactured by direct metal laser sintering," Eng. Struct., vol. 201, no. December, p. 109838, 2019.

[2] Q. Gao, L. Wang, Y. Wang, and C. Wang, "Crushing analysis and multiobjective crashworthiness optimization of foam-filled ellipse tubes under oblique impact loading," Thin-Walled Struct., 2016, doi: 10.1016/j.tws.2015.11.020.

[3] F. Tarlochan, F. Samer, A. M. S. Hamouda, S. Ramesh, and K. Khalid, "Design of thin wall structures for energy absorption applications: Enhancement of crashworthiness due to axial and oblique impact forces," Thin-Walled Struct., vol. 71, pp. 7-17, 2013.

https://doi.org/10.1016/j.tws.2013.04.003

[4] Z. Fan, G. Lu, and K. Liu, "Quasi-static axial compression of thin-walled tubes with different cross-sectional shapes," Eng. Struct., vol. 55, pp. 80-89, 2013.

[5] A. E. Ismail and M. F. Sahrom, "Lateral crushing energy absorption of cylindrical kenaf fiber reinforced composites," Int. J. Appl. Eng. Res., vol. 10, no. 8, pp. 19277-19288, 2015.

[6] A. E. Ismail and M. A. Che Abdul Aziz, "Tensile strength of woven yarn kenaf fiber reinforced polyester composites," J. Mech. Eng. Sci., vol. 9, pp. 1695-1704, 2015.

https://doi.org/10.15282/jmes.9.2015.15.0163

[7] O. H. Mete, M. Yalcin, and K. Genel, "Experimental and numerical studies on the folding response of annular-rolled Al tube," Thin-Walled Struct., 2018, doi: 10.1016/j.tws.2018.03.015.

[8] J. Marzbanrad, M. Mehdikhanlo, and A. S. Pour, "An energy absorption comparison of square, circular, and elliptic steel and aluminum tubes under impact loading," Turkish J. Eng. Environ. Sci., vol. 33, no. 3, pp. 159-166, 2010.

[9] H. Nikkhah, F. Guo, Y. Chew, J. Bai, J. Song, and P. Wang, "The effect of different shapes of holes on the crushing characteristics of aluminum square windowed tubes under dynamic axial loading," Thin-Walled Struct., vol. 119, pp. 412-420, 2017.

[10] A. Moradpour, M. Elyasi, and S. Montazeri, "Developing a new thin-walled tube structure and analyzing its crushing performance for aa $\mathbf{6 0 6 0 1}$ and mild steel under axial loading," Trans. Indian Inst. Met., vol. 69, no. 5, pp. 1107-1117, 2016.

https://doi.org/10.1007/s12666-015-0629-2

[11] M. Bulik, M. Liefvendahl, R. Stocki, and C. Wauquiez, "Stochastic simulation for crashworthiness," Adv. Eng. Softw., vol. 35, no. 12, pp. 791-803, 2004.
[12] H. Wang, G. Y. Li, and E. Li, "Time-based metamodeling technique for vehicle crashworthiness optimization," Comput. Methods Appl. Mech. Eng., vol. 199, no. 37-40, pp. 2497-2509, 2010.

[13] R.-Y. Yao, B. Zhang, G.-S. Yin, and Z.-Y. Zhao, "Energy absorption behaviors of foam-filled holed tube subjected to axial crushing: Experimental and theoretical investigations," Mech. Adv. Mater. Struct., pp. 1-14, 2020.

[14] O. T. Cherney, S. ZhannaV, L. I. Kutepova, S. M. Maltseva, and M. M. Kutepov, "Prospective Aluminum alloys for the production of soldered structures," Int. J., vol. 8, no. 6, 2020. https://doi.org/10.30534/ijeter/2020/04862020

[15] V. S. Popov, A. F. Kolbasov, and K. E. Karpukhin, "Mathematical Simulation of Thermal Stress State of Microturbine Casing Shell Elements," Int. J., vol. 8, no. 6, 2020.

https://doi.org/10.30534/ijeter/2020/88862020

[16] W. Witteman, "Improved vehicle crashworthiness design by control of the energy absorption for different collision situations," $P h$. D. Thesis, Univ. Technol. Automot. Eng. Prod. Des. Technol. Eindhoven, Netherlands, 1999.

[17] G. Lu and T. X. Yu, Energy absorption of structures and materials. Elsevier, 2003.

[18] B. Dehghan-Manshadi, H. Mahmudi, A. Abedian, and R. Mahmudi, "A novel method for materials selection in mechanical design: combination of non-linear normalization and a modified digital logic method," Mater. Des., vol. 28, no. 1, pp. 8-15, 2007.

[19] Z. Ahmad and D. P. Thambiratnam, "Dynamic computer simulation and energy absorption of foam-filled conical tubes under axial impact loading," Comput. Struct., vol. 87, no. 3-4, pp. 186-197, 2009.

https://doi.org/10.1016/j.compstruc.2008.10.003

[20] A.E. Ismail, M.A. Hassan, "Low velocity impact on woven kenaf fiber reinforced composites", Applied Mechanics and Materials, Vol. 629, pp. 503-506, 2014.

[21] S.N.A. Khalid, A.E. Ismail, M.H. Zainulabidin, A.M. Tajul Arifin, M.F. Hassan, M.R.I brahim, M.Z. Rahim, "Mechanical performances of twill kenaf woven fiber reinforced polyester composites", International Journal of Integrated Engineering, Vol. 10, Issue 4, pp. 49-59, 2018.

[22] A.E. Ismail, A.K. Ariffin, S. Abdullah, M.J. Ghazali, "Stress intensity factors under combined tension and torsion loadings", Indian Journal of Engineering and Materials Sciences, Vol. 19, Issue 1, pp. 5-16, 2012.

[23] A.E. Ismail, A.K. Ariffin, S. Abdullah, M.J. Ghazali, R. Daud, "Mode III stress intensity factors of surface crack in round bars", Advanced Materials 
Jeffery Jep Brown et al., International Journal of Emerging Trends in Engineering Research, 8(8), August 2020, 4084 - 4090

Research, Vol. 214, pp. 192-196, 2011.

[24] A.E. Ismail, M.H. Zainulabidin, M.N. Roslan, A.L. Mohd Tobi, N.H. Muhd Nor, "Effect of velocity on the impact resistance of woven jute fiber reinforced composites", Applied Mechanics and Materials, Vol. 465-466, pp. 1277-1281, 2014.

[25] A.E. Ismail, A.L. Mohd Tobi, "Axial energy absorption of woven kenaf fiber reinforced composites", ARPN Journal of Engineering and Applied Sciences, Vol. 11, Issue 14, pp. 8668-8672, 2016. 